\title{
Synthetic Immunomodulatory Peptide IDR-1002 Enhances Monocyte Migration and Adhesion on Fibronectin
}

\author{
Laurence Madera Robert E.W. Hancock \\ Centre for Microbial Diseases and Immunity Research, Department of Microbiology and Immunology, University of \\ British Columbia, Vancouver, B.C., Canada
}

\section{Key Words}

Adhesion - Fibronectin - IDR peptides •

Immunomodulation $\cdot$ Integrin regulation $\cdot$ Monocyte

migration $\cdot \mathrm{PI} 3 \mathrm{~K}-\mathrm{Akt}$

\begin{abstract}
Regulation of the immune system by immunomodulatory agents, such as the synthetic innate defense regulator (IDR) peptides, has been proposed as a potential strategy to strengthen host immune responses against infection. IDR peptides confer protection in vivo against a range of bacterial infections and have been developed as components of single-dose vaccine adjuvants due to their ability to modulate innate immunity, correlating with an increased recruitment of monocytes to sites of infection or immunization. However, the mechanisms by which IDR peptides augment monocyte recruitment remain poorly defined. Anti-infective peptide IDR-1002 was demonstrated here to lack direct monocyte chemoattractive activity yet enhance, by up to 5 -fold, the ability of human monocytes to migrate on fibronectin towards chemokines. This effect correlated with an increased adhesion of monocytes and THP-1 cells to fibronectin by IDR-1002 and other IDR peptides and the adhesion
\end{abstract}

of THP-1 cells to fibronectin occurred in a $\beta_{1}$-integrin-dependent manner, corresponding with an increased activation of $\beta_{1}$-integrins and the phosphoinositide 3-kinase (PI3K)-Akt pathway. PI3K- and Akt-specific inhibitors abrogated IDR1002-induced adhesion and activation of $\beta_{1}$-integrins, whereas p38 and MEK1 inhibitors did not affect, or moderately inhibited, adhesion, respectively. Furthermore, IDR1002 enhancement of monocyte migration towards chemokines and activation of $\beta_{1}$-integrins was abrogated in the presence of PI3K- and Akt-specific inhibitors. In summary, IDR-1002 enhanced monocyte migration on fibronectin through promotion of $\beta_{1}$-integrin-mediated interactions regulated by the PI3K-Akt pathway, revealing a mechanism by which IDR-1002 promotes monocyte recruitment.

Copyright $\odot 2012$ S. Karger AG, Basel

\section{Introduction}

The troubling rise of antibiotic-resistant pathogens necessitates the development of novel therapeutic strategies to combat bacterial infections. One such strategy under investigation is that of immunomodulation, the regulation and augmentation of host immune responses with

\section{KARGER}

Fax +41613061234

E-Mail karger@karger.ch

www.karger.com
(C) 2012 S. Karger AG, Basel

$1662-811 X / 12 / 0046-0553 \$ 38.00 / 0$

Accessible online at:

www.karger.com/jin
Prof. Robert E.W. Hancock

Centre for Microbial Diseases and Immunity Research

Department of Microbiology and Immunology, University of British Columbia

2259 Lower Mall Research Station, Vancouver, BC V6T 1Z4 (Canada)

Tel. +1 604822 2682, E-Mail bob@cmdr.ubc.ca 
the aim of enhancing bacterial clearance during infection. Derivatives of natural host defense peptides (HDPs) are being studied as potential immunomodulatory antiinfective agents. Host defense (also termed antimicrobial) peptides encompass structurally diverse families of cationic amphipathic molecules, which are widely expressed in virtually every class of life $[1,2]$. Although originally viewed as direct antimicrobial agents, it is becoming increasingly clear that these peptides broadly modulate the immune response. HDP immunomodulatory activities, in both in vitro and in animal models, include the direct promotion of chemotaxis and stimulation of chemokine production, promoting phagocyte infiltration into infected sites. These peptides also regulate immune cell function, enhancing leukocyte antimicrobial activity and modulating cellular differentiation of dendritic cells and macrophages. In addition, HDPs can suppress potentially harmful pro-inflammatory responses stimulated by bacterial products, promote epithelial cell migration and growth, and stimulate wound healing and angiogenesis. The comprehensive effects of such peptides make them promising templates for the development of novel anti-infective therapeutics.

The development of innate defense regulator (IDR) peptides represents an effort to exploit and improve upon the anti-infective properties of HDPs. Originating from a peptide library of sequence-modified bactenecin derivatives, IDR peptide candidates were screened for their ability to induce chemokine production in vitro as an indicator of immunomodulation. Numerous IDR peptides exhibiting potent chemokine-inducing properties have thus demonstrated the ability to protect against bacterial infection in vivo through selective enhancement of antibacterial innate immunity. IDR-1, a peptide lacking direct antimicrobial activity, confers prophylactic and therapeutic protection against systemic infections with multidrug-resistant bacteria in mouse models [3]. This protection correlates with the enhancement of chemokine production, suppression of potentially harmful inflammatory cytokines and an increase in macrophage counts at the site of infection. A derivative of IDR-1, IMX942, developed by Inimex Pharmaceuticals, has demonstrated a strong safety profile in phase I clinical trials. IDR-1002, a remote derivative of bovine bactenecin, confers increased in vivo protection against bacterial infections, an effect that is also associated with the enhancement of chemokine production as well as an increase in neutrophils and monocyte recruitment to the site of infection [4]. It has also been developed and outlicensed as a component of an adjuvant formulation, com- prising IDR-1002, CpG oligonucleotide and polyphosphazene. In this adjuvant formulation, which enables effective single-dose vaccines against pertussis, its primary role is to enhance recruitment of immune cells $[5,6]$. Although IDR peptides demonstrate potent anti-infective and adjuvant properties, our limited understanding regarding the mechanisms by which IDR peptides modulate immunity represents an obstacle in their development as clinical therapeutic agents.

Augmentation of monocyte recruitment to the site of infection appears to be an important step in IDR-mediated protection, an observation supported by the abolishment of IDR protection in a monocyte-/macrophagedepleted animal $[3,4]$. An understanding of how IDR peptides reinforce monocyte recruitment to the site of infection or immunization is essential to the development of improved multifunctional immunomodulatory agents with increased anti-infective properties. Studies have focused on the ability of IDR peptides to indirectly promote cell recruitment via stimulation of chemokine production by host cells, whereas IDR-mediated enhancement of leukocyte recruitment is a highly rapid occurrence [4]. This implicates a yet undiscovered mechanism by which IDR peptides directly modulate leukocyte migratory behavior.

Monocyte recruitment is a complex process which relies on monocyte interactions with its surrounding environment to provide signals which coordinate cellular migratory behavior. Monocyte adhesion to tissues has been shown to play an important role in monocyte locomotion and migration [7] and is largely mediated by the interactions of integrins with their various ligands, including cellular adhesion molecules on endothelial surfaces or a number of component molecules of the extracellular matrix (ECM). In this study, we investigated the effects of IDR-1002 on monocyte migration on, and attachment to, fibronectin, a glycoprotein present in the ECM networks of many tissues [8]. We demonstrated that IDR-1002 rapidly induced $\beta_{1}$-integrin-mediated monocyte adhesion to fibronectin and enhanced monocyte chemotaxis towards natural chemokines through a fibronectin-coated membrane. The enhanced monocyte-fibronectin interaction elicited by IDR-1002 was dependent on its activation of the phosphoinositide 3-kinase (PI3K)-Akt pathway and downstream activation of $\beta_{1}$-integrins. These results suggest that IDR peptides enhance cell recruitment through their regulation of monocyte signaling networks and subsequent modulation of integrin function, illustrating a previously unreported mechanism for the IDR-mediated augmentation of host defense. 


\section{Methods}

\section{Reagents}

Peptides LL-37 (LLGDFFRKSKEKIGKEFKRIVQRIKDFLRNLVPRTES-NH ${ }_{2}$ ), IDR-1002 (VQRWLIVWRIRK-NH ${ }_{2}$ ), IDR$\mathrm{HH} 2$ (VQLRIRVAVIRA- $\mathrm{NH}_{2}$ ) and IDR-1018 (VRLIVAVRIWRR- $\mathrm{NH}_{2}$ ) were synthesized by solid-phase F-moc chemistry by CPCScientific(Sunnyvale, Calif.,USA).IDR-1(KSRIVPAIPVSLL$\mathrm{NH}_{2}$ ) and negative control peptide 1035 (KRWRWIVRNIRR$\mathrm{NH}_{2}$ ) were similarly synthesized by the Biomedical Research Center (University of British Columbia, Vancouver, B.C., Canada). Phorbol myristate acetate (PMA) was resuspended in dimethyl sulfoxide (DMSO; both from Sigma-Aldrich, St. Louis, Mo., USA) and stored at $-20^{\circ} \mathrm{C}$. PI3K inhibitor LY294002, Akt inhibitor SH-5, p38 mitogen-activated protein kinase (MAPK) inhibitor SB203580 and MEK1 MAPK inhibitor PD98059 (all from Calbiochem, San Diego, Calif., USA) were resuspended in DMSO and stored at $-20^{\circ} \mathrm{C}$. In inhibitor experiments, the concentrations of DMSO used never exceeded $0.1 \%(\mathrm{v} / \mathrm{v})$ in cell cultures. The $\mathrm{G}_{\mathrm{i}^{-}}$ protein inhibitor pertussis toxin was also obtained from Calbiochem. Chemokines MCP-1/CCL2, MCP-3/CCL7, MIP-1 $\alpha / C C L 3$ and RANTES/CCL5 were obtained from R\&D Systems (Minneapolis, Minn., USA).

\section{Cell Isolation and Culture}

Human peripheral blood mononuclear cells (PBMCs) were isolated as previously reported [9]. Briefly, venous blood was collected from healthy volunteers using heparin-containing Vacutainer tubes (BD Bioscience, San Jose, Calif., USA) in accordance with University of British Columbia ethical approval and guidelines. Human blood was diluted in an equal amount of PBS (Invitrogen, Carlsbad, Calif., USA) then layered over Ficoll-Paque Plus (Amersham, Piscataway, N.J., USA) prior to separation by density gradient centrifugation. The mononuclear cell layer was extracted and washed twice with PBS. The monocyte population was enriched by negative selection magnetic bead purification from the PBMCs using the Easy-Sep Human Monocyte Enrichment Kit (Stemcell Technologies, Vancouver, B.C., Canada) as per the manufacturer's instructions. Monocytes were then resuspended in RPMI 1640 with $10 \%$ (v/v) heat-inactivated FBS, 2 mM TLT-glutamine, and $1 \mathrm{~mm}$ sodium pyruvate (all from Invitrogen), placed in a polypropylene tube (BD Falcon, San Jose, Calif., USA) and cultured in a humidified incubator at $37^{\circ} \mathrm{C}$ with $5 \% \mathrm{CO}_{2}$. The human monocytic cell line THP-1 [10] (ATCC TIB-202; American Type Culture Collection, Manassas, Va., USA) was cultured in the same media and conditions, as stated above, for a maximum of five passages.

\section{Fibronectin Adhesion Assay}

Polystyrene tissue culture plates (BD Falcon) were coated overnight at $4{ }^{\circ} \mathrm{C}$ with $50 \mu \mathrm{g} / \mathrm{ml}$ of human plasma fibronectin (Calbiochem) per well. The wells were then washed with PBS prior to blocking with PBS containing 1\% (w/v) BSA (Roche, Basel, Switzerland) for $1 \mathrm{~h}$ at $37^{\circ} \mathrm{C}$. Wells were washed again with PBS prior to use. Wells without fibronectin were also blocked with $1 \%$ BSA as controls for nonspecific adhesion.

Human blood monocytes and THP-1 cells were resuspended in RPMI 1640 with $1 \%$ FBS at a density of $5 \times 10^{5}$ cells $/ \mathrm{ml}$ for $1 \mathrm{~h}$. For PI3K-Akt inhibition studies, cells were then pretreated with chemical inhibitors, or a DMSO vehicle control, at the indicated concentrations for $1 \mathrm{~h}$. Similarly for $\beta_{1}$-integrin blocking studies, cells were pretreated with an anti-human $\beta_{1}$-integrin functional blocking monoclonal antibody (mAb; P4C10; Millipore, Billerica, Mass., USA) at the indicated concentrations or $20 \mu \mathrm{g} / \mathrm{ml}$ of a mouse $\mathrm{IgG}_{1}$ isotype antibody (MG1-45; Biolegend, San Diego, Calif., USA) for 1 h. $5 \times 10^{4}$ cells were added to each well and stimulated with the indicated treatments. PMA at $50 \mathrm{ng} / \mathrm{ml}$ was used as a positive control for monocyte-fibronectin binding in some experiments. The cells were incubated at $37^{\circ} \mathrm{C}$ for $3 \mathrm{~h}$, unless otherwise stated. The cells were then removed and the wells washed twice with PBS prior to upside-down centrifugation at $50 \mathrm{~g}$ for $5 \mathrm{~min}$ to remove non-adherent cells. Wells were washed twice with PBS and adherent cells were stained with the DiffQuick staining kit (VWR Scientific Products, Radnor, Pa., USA) as per the manufacturer's instructions.

Measurement of adhesion levels were done by averaging the counts of cells over 6 high power fields (HPF; magnification: $\times 200$ ) under phase-contrast microscopy with a light microscope. Counts per HPF of adherent cells on non-fibronectin-coated, BSA-blocked wells were subtracted from counts of fibronectincoated wells without stimulation for each treatment to assess fibronectin-specific monocyte adhesion.

\section{Flow Cytometry to Determine $\beta_{1}$-Integrin Levels and Akt Phosphorylation}

All flow cytometry results were collected using the FACSCalibur flow cytometer in conjunction with CellQuest Pro software (BD Biosciences). THP-1 cells were resuspended in RPMI 1640 with $1 \%$ FBS at a density of $1 \times 10^{6}$ cells $/ \mathrm{ml} ; 2 \times 10^{5}$ cells per well were then seeded on tissue culture plates and placed in a humidified incubator at $37^{\circ} \mathrm{C}$ and $5 \% \mathrm{CO}_{2}$ for $1 \mathrm{~h}$. For inhibitor studies, THP-1 cells were then pretreated with chemical inhibitors, or a DMSO vehicle control, at the indicated concentrations for $1 \mathrm{~h}$. Cells were then stimulated with the indicated treatments for the indicated time points and incubated at $37^{\circ} \mathrm{C}$ for $3 \mathrm{~h}$. Following treatment, THP-1 cells were then fixed with PBS and $4 \%(\mathrm{w} / \mathrm{v})$ formaldehyde (Fisher Scientific, Pittsburgh, Pa., USA) at room temperature for $20 \mathrm{~min}$ in preparation for staining.

To investigate $\beta_{1}$-integrin surface expression, THP-1 cells were washed using PBS with $0.5 \%$ BSA and stained at room tem-

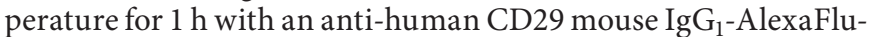
or ${ }^{\circledR} 647$ (TS2/16, Biolegend) or an $\mathrm{mAb}$ specific for the active conformation of human $\beta_{1}$-integrins (HUTS-4; Millipore). THP-1 cells were also stained, in parallel, with a mouse IgG $_{1}$ antibody conjugated to AlexaFluor 647 (MOPC-21; Biolegend) or a mouse $\mathrm{IgG}_{2 \mathrm{~b}}$ isotype antibody (MPC-11; Biolegend) as respective isotype controls. For the determination of activated $\beta_{1}$-integrin levels, THP-1 cells were then washed and further stained with a goat anti-mouse IgG-DyLight ${ }^{\mathrm{TM}} 649$ (Poly4053; Biolegend) antibody for $30 \mathrm{~min}$ at room temperature. Cells were then washed and resuspended in PBS with $0.5 \%$ BSA and $0.5 \%$ formaldehyde for analysis. Protein expression levels for each sample were determined by measuring the geometric mean fluorescence intensity (MFI) levels of 1,000 cells, subtracted by MFI levels of their isotype-stained counterparts. The displayed fold changes over basal values were calculated by dividing the corrected MFI values of each treatment by the MFI values of the untreated sample of their respective time point and inhibitor conditions.

To investigate the intracellular levels of phosphorylated Akt, THP-1 cells were washed with $0.5 \%$ BSA and permeabilized in 
$90 \%(\mathrm{v} / \mathrm{v})$ methanol at $4^{\circ} \mathrm{C}$ for $30 \mathrm{~min}$. The cells were then washed and stained at room temperature for $1 \mathrm{~h}$ with phospho-Akt (Ser473) $193 \mathrm{H} 12$ rabbit $\mathrm{mAb}$ or a DA1E rabbit IgG isotype $\mathrm{mAb}$ (both from Cell Signaling Technology, Danvers, Mass., USA). Following washing, the cells were stained with a goat anti-rabbit IgG-Alexa Fluor $647(\mathrm{H}+\mathrm{L}$; Invitrogen) for $30 \mathrm{~min}$ at room temperature. The cells were then washed and resuspended in PBS with $0.5 \%$ BSA and $0.5 \%$ formaldehyde for analysis. Levels of phosphorylated Akt for each sample were determined by measuring the MFI levels of 1,000 cells, subtracted by MFI levels of their corresponding isotype-stained samples. The displayed fold changes over basal values were calculated by dividing the corrected MFI values of each treatment by the MFI values of the untreated sample of their respective time point and inhibitor conditions.

\section{Fibronectin Migration Assay}

All migration assays were performed using a 48-well microchemotaxis chamber (Neuro Probe). Freshly enriched human peripheral blood monocytes were adjusted to RPMI 1640 with $1 \%$ FBS and incubated at $37^{\circ} \mathrm{C}$ for $1 \mathrm{~h}$. For inhibitor studies, monocytes were pretreated with chemical inhibitors, or a DMSO vehicle control, at the indicated concentrations for $1 \mathrm{~h}$. Similarly in $\beta_{1}$-integrin blocking experiments, monocytes were pretreated with $20 \mu \mathrm{g} / \mathrm{ml}$ of a HUTS-4-blocking antibody or an isotypematched mouse IgG $\mathrm{G}_{1}$ control antibody for $1 \mathrm{~h} ; 5 \times 10^{4}$ monocytes were added to the upper wells of the chamber, and indicated concentrations of chemokines in RPMI 1640 with $1 \%$ FBS were added to the lower wells. Lower wells containing RPMI 1640 and 1\% FBS were used as negative controls. In IDR-1002-chemokine synergy studies, treatment with IDR-1002 was done by adding peptide to both upper and lower wells to avoid a concentration gradient. The upper and lower wells were separated by a polycarbonate membrane with $5-\mu \mathrm{m}$-diameter pores. Membranes were precoated with $50 \mu \mathrm{g} / \mathrm{ml}$ of fibronectin at $4^{\circ} \mathrm{C}$ overnight, washed with PBS and air-dried prior to use. After $1 \mathrm{~h}$ of incubation, non-migrated monocytes were removed by PBS washing and scraping with a rubber blade and adherent cells on the underside of the membrane were stained with the Diff-Quick staining kit.

Control experiments assessing the effects of IDR-1002 on monocyte migration independent of chemokines were similarly done. To investigate any direct chemotactic properties of IDR1002, different concentrations of IDR-1002 were added to the lower wells of the chemotaxis chamber and separated from the monocyte-containing chamber with a non-coated polycarbonate membrane. Likewise, migration experiments investigating the chemotactic or chemokinetic properties of IDR-1002 in a fibronectin system were done by the addition of the indicated amount of peptide to both the upper and lower wells in chemokinesis experiments, and lower wells alone in chemotaxis experiments. The wells were then separated with a fibronectin-coated polycarbonate membrane and processed using the method stated above.

Migration for each treatment was measured by averaging the number of migrated cells per HPF over 5 fields with each treatment condition done in duplicate. Fold change over control values were calculated by dividing the average cell count per HPF of each treatment by the average cell count per HPF of basal migration in media alone.

\section{Results}

\section{Enhancement of Monocyte Migration on Fibronectin} by IDR-1002

To investigate the mechanisms underlying the enhancement of monocyte migration by IDR-1002, an in vitro model using human monocytes was established. We hypothesized that IDR-1002 would regulate the migratory activity of monocytes towards natural mediators of chemotaxis expressed during an infection, such as host chemokines. The ability of IDR-1002 to promote chemotaxis across an uncoated membrane filter was tested, but little or no migration was observed, demonstrating a lack of chemotactic activity by IDR-1002 (online suppl. fig. 1; for all online supplementary material, see www. karger.com/doi/10.1159/000338648); therefore, the effects of molecules that are known to promote cell migration were tested. It was observed that in the presence of fibronectin, IDR-1002 substantially enhanced the ability of human blood monocytes to migrate towards a range of chemokines. The degree of monocyte migration across a fibronectin-coated membrane was determined by microscopy after $1 \mathrm{~h}$. As shown in figure 1, varying concentrations of monocyte chemokines CCL2, CCL7, CCL3 and CCL5 increased the migration of monocytes across a fibronectin-coated membrane compared to baseline migration of monocytes in medium alone, as expected (NB: control peptide 1035 showed no enhancement of migration - see below). Baseline migration of monocytes after $1 \mathrm{~h}$ was estimated to be nearly $2 \%$ of the starting monocyte population. In the presence of IDR-1002, the numbers of migrating monocytes towards the chemokines were significantly increased. IDR-stimulated monocytes induced monocyte migration by up to fivefold from baseline migration levels, a nearly twofold increase compared to chemokine-induced migration, demonstrating an enhancement of monocyte chemotactic activity. Migration through fibronectin of monocytes treated with IDR-1002 in the absence of chemokines did not differ from the spontaneous migration of media-only control treatments, indicating a lack of chemokinetic activity by IDR1002 (online suppl. fig. 2A), nor did migration towards IDR-1002-containing wells differ from migration towards media-only wells, demonstrating a lack of chemotactic activity in a fibronectin model as well (online suppl. fig. 2B). Thus, the observed promotion of migration by IDR-1002 indicates synergistic enhancement of monocyte migratory behavior on fibronectin towards chemokines.

As IDR-1002 displayed an enhancement of chemotaxis towards all tested chemokines, the ability of IDR-1002 

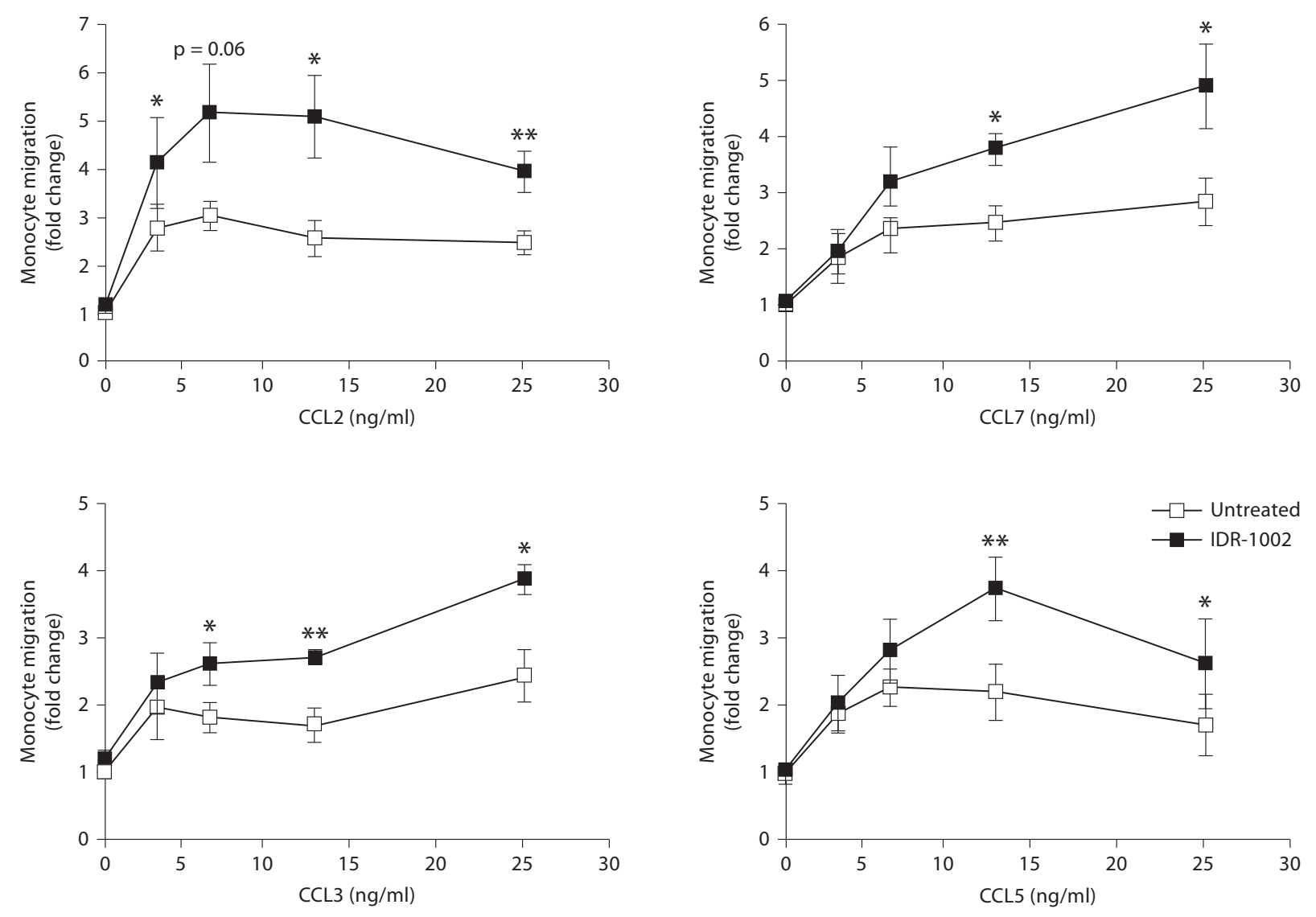

Fig. 1. IDR-1002 enhancement of monocyte migration on fibronectin. Effects of IDR-1002 (20 $\mu \mathrm{g} / \mathrm{ml})$ on monocyte chemotaxis towards varying levels of chemokines $(3.125,6.25,12.5$ and $25 \mathrm{ng} / \mathrm{ml})$ through a fibronectin-coated membrane. Data are presented as fold increases in migration over baseline migration in media alone $( \pm \mathrm{SE})$ of at least 4 independent experiments, each from independent donors. Student's two-tailed t test: ${ }^{*} \mathrm{p}<0.05 ;{ }^{* *} \mathrm{p}<0.01$.

to promote monocyte-fibronectin interactions was investigated, since cellular adhesion to fibronectin is known to facilitate monocyte migration through a number of environments, including the basement membrane of the endothelia and the ECM [11]. The interactions between monocytes and surrounding substrates, such as endothelial surface and ECM components, are highly dependent on the actions of the integrin family of receptors. Monocyte adhesion to fibronectin is primarily mediated by the $\beta_{1}$ family of integrins, which include the monocyte adhesion receptors VLA-4 and $\alpha_{5} \beta_{1}[12,13]$. Previous treatment of monocytes with $20 \mu \mathrm{g} / \mathrm{ml}$ of a $\beta_{1}$-integrin-inhibiting antibody abolished the enhancing effect of IDR1002 on monocyte chemotaxis towards CCL2 and CCL7, compared to monocytes pretreated with an isotypematched antibody control (fig. 2). Inhibition of $\beta_{1}$-integrin function greatly reduced, but did not eliminate, the augmentation of monocyte migration towards CCL3 and CCL5 by IDR-1002. This observation correlated with studies using uncoated membranes which demonstrated specific enhancement of monocyte migration by IDR1002 towards CCL3 and CCL5, suggesting alternative mechanisms through which IDR-1002 can promote monocyte recruitment [unpubl. data]. Overall, these results showed that the $\beta_{1}$-integrins play a large role in the promotion of monocyte chemotaxis by IDR-1002, likely through the enhanced interaction between monocytes and the fibronectin-coated membrane. IDR-1002 did not 


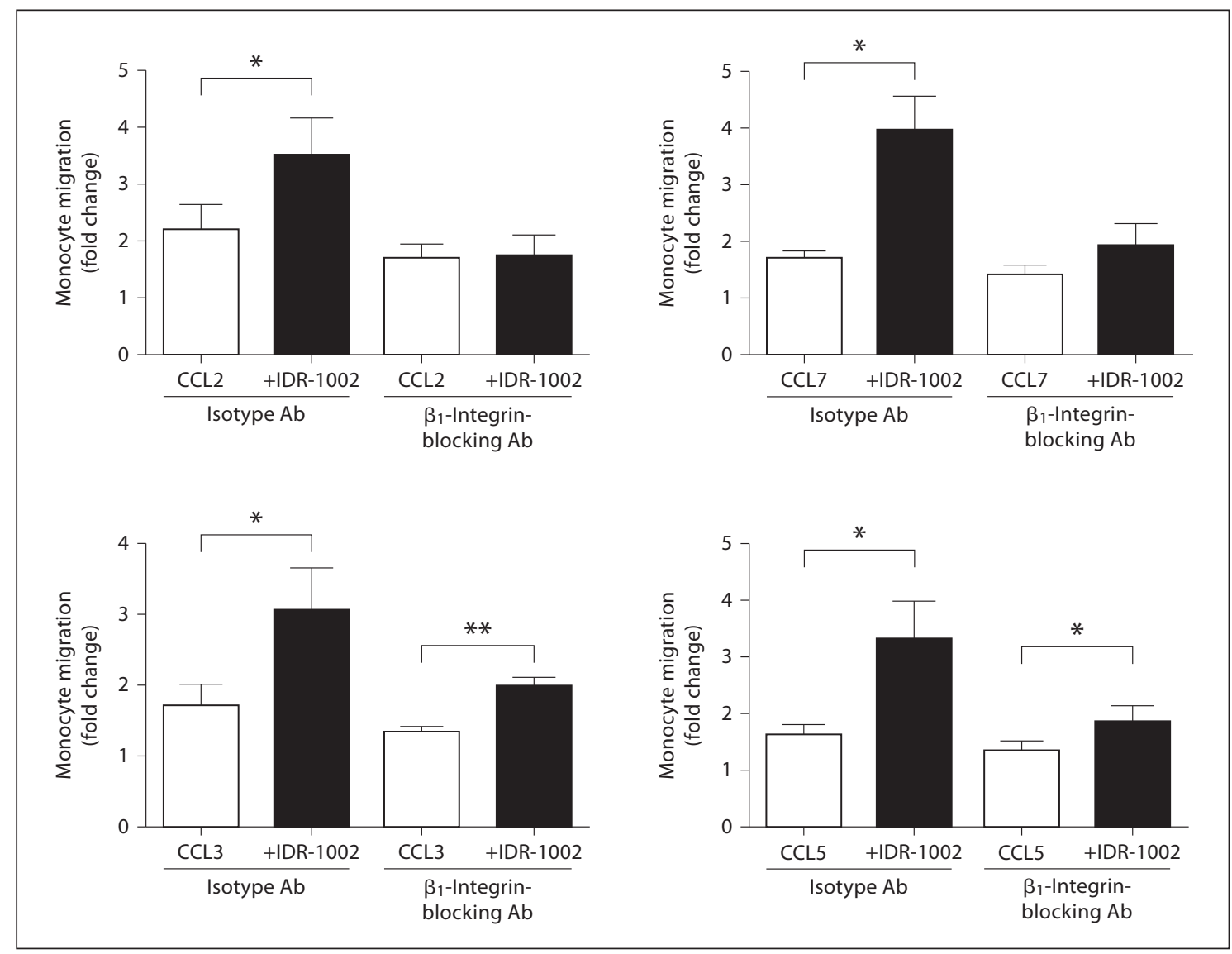

Fig. 2. The role of $\beta_{1}$-integrins in IDR-1002-mediated enhancement of monocyte migration. Monocytes were pretreated with a $\beta_{1}$-integrin-inhibiting antibody or an isotype-matched control antibody $(20 \mu \mathrm{g} / \mathrm{ml})$ for $1 \mathrm{~h}$. Monocytes were then assessed for their ability to migrate towards chemokines $(12.5 \mathrm{ng} / \mathrm{ml})$ through a fibronectin-coated membrane with or without IDR-1002 $(20 \mu \mathrm{g} / \mathrm{ml})$ treatment. Data are presented as fold increases in migration over isotype-antibody-treated monocyte migration in media alone $( \pm \mathrm{SE})$ of at least 4 independent experiments, each from independent donors. Student's two-tailed t test: ${ }^{*} \mathrm{p}<0.05 ;{ }^{* *} \mathrm{p}<0.01$.

significantly alter the migration of isotype-antibodytreated or $\beta_{1}$-integrin-treated monocytes in the absence of chemokines (data not shown).

\section{Regulation of Monocyte Adhesion to Fibronectin by IDR-1002}

To elucidate the potential regulation of $\beta_{1}$-integrinmediated binding by IDR-1002, we investigated whether IDR-1002 could promote monocyte adhesion to fibronectin. Human blood monocytes or THP-1 cells were treated with varying doses of IDR-1002 and assessed for their ability to adhere to fibronectin-coated plates. The degree of adhesion at $3 \mathrm{~h}$ was determined by microscopy after the removal of unattached cells. IDR-1002 demonstrated a dose-dependent and very substantial increase in adhe- sion to fibronectin of either blood monocytes or THP-1 cells, indicating a promotion of monocyte-fibronectin interactions (fig. 3a). Although blood monocytes demonstrated increased sensitivity to lower IDR-1002 concentrations compared to a THP-1 model, the adhesion patterns of IDR-1002-stimulated monocytes and THP-1 cells were similar. Thus, we elected to use THP-1 cells as an alternative model to further investigate monocyte adhesion behavior.

Monocyte adhesion and migration is a rapid event. Monocyte adhesive interactions with various substrates can be differentially regulated in as little as a few minutes $[14,15]$. The rapid regulation of adhesion in response to extracellular stimuli, such as chemokines, is a necessity for substrate-mediated monocyte motility, which re- 

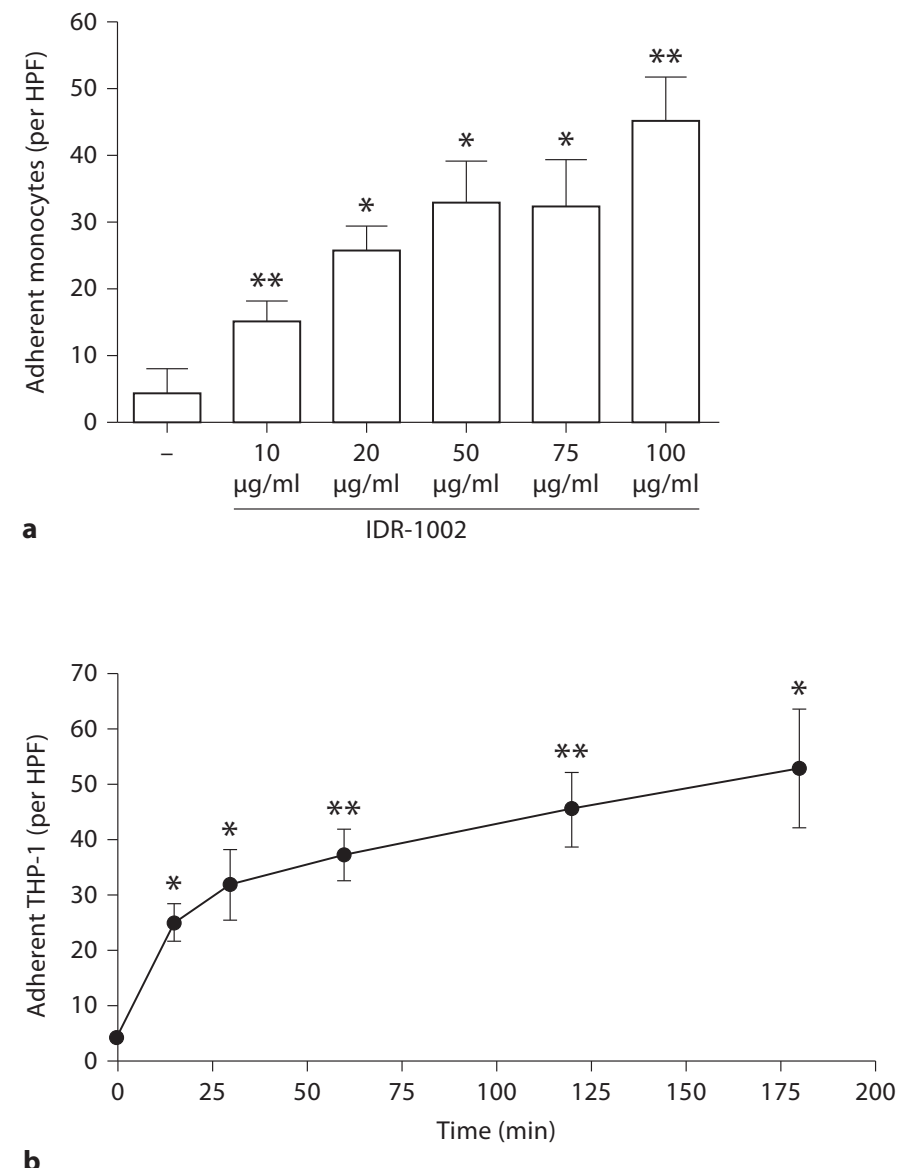
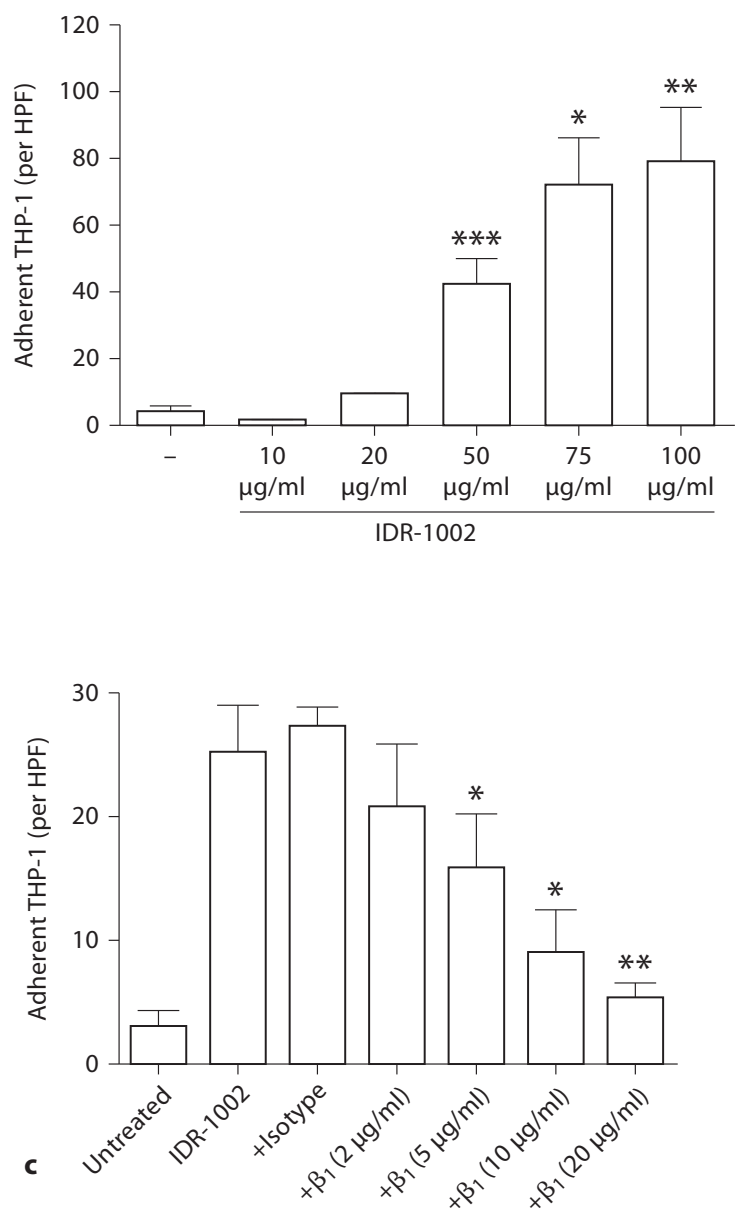

Fig. 3. IDR-1002 regulation of monocyte adhesion on fibronectin. a Monocytes or THP-1 cells were stimulated with various concentrations of IDR-1002 for $3 \mathrm{~h}$ and assayed for their ability to adhere. b Time course effects of IDR-1002 $(50 \mu \mathrm{g} / \mathrm{ml})$ on THP-1 adhesion. c Effects of $\beta_{1}$-integrin inhibition on adhesion of THP-1 cells stimulated with IDR-1002 $(50 \mu \mathrm{g} / \mathrm{ml})$. THP-1 cells were pretreated with a $\beta_{1}$-integrin-inhibiting antibody or an isotype-matched control antibody $(20 \mu \mathrm{g} / \mathrm{ml})$ for $1 \mathrm{~h}$, stimulated with IDR-1002 for $3 \mathrm{~h}$ and assayed for their ability to adhere. Data are presented as the mean of adherent cells per HPF $( \pm S E)$ of at least 3 independent experiments. In experiments using primary monocytes, each independent experiment utilized cells from an independent donor. Student's two-tailed t test: ${ }^{*} \mathrm{p}<0.05 ;{ }^{* *} \mathrm{p}<0.01 ;{ }^{* * *} \mathrm{p}<0.001$. quires the coordinated engagement and disengagement of adhesion receptors to their environmental ligands. Thus the temporal profile of IDR-1002-mediated adhesion to fibronectin was determined. THP-1 cells on fibronectin-coated plates were stimulated with IDR-1002 for varying amounts of time prior to removal of non-adherent cells. Time course adhesion experiments showed that IDR-1002-induced THP-1 adhesion to fibronectin was rapid, with significant adhesion observed as early as 15 min. A continued increase in THP-1 adhesion was evident up to $3 \mathrm{~h}$ after IDR stimulation (fig. $3 \mathrm{~b}$ ).

IDR-1002 Enhances Monocyte Migration and Adhesion on Fibronectin
Next it was determined whether the adhesive activity of IDR-1002 was mediated specifically through the binding activity of the $\beta_{1}$-integrins. THP-1 cells were pretreated with varying doses of a $\beta_{1}$-integrin-inhibiting antibody $1 \mathrm{~h}$ prior to stimulation with IDR-1002. The addition of a $\beta_{1}$-integrin-inhibiting antibody resulted in a dose-dependent inhibition of THP-1 adhesion to fibronectin-coated plates, fully abrogating IDR-1002-mediated adhesion at an antibody concentration of $20 \mu \mathrm{g} / \mathrm{ml}$ (fig. 3c). In contrast, pretreatment of THP-1 cells with 20 $\mu \mathrm{g} / \mathrm{ml}$ of an isotype-matched antibody had no effect on 

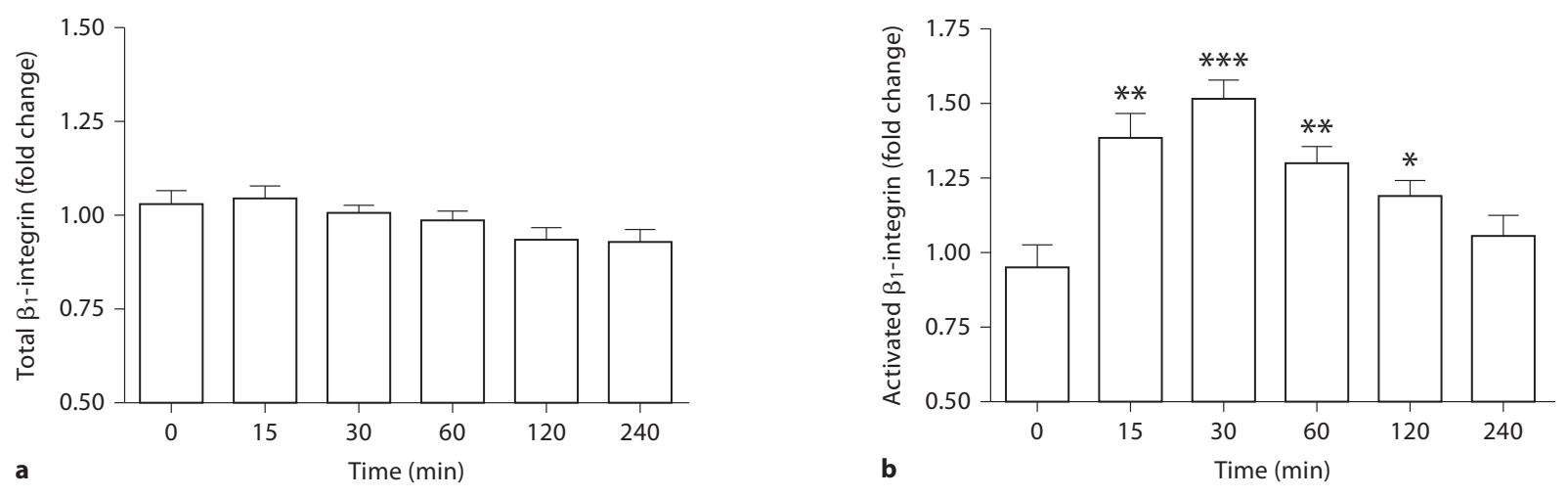

Fig. 4. IDR-1002 regulation of $\beta_{1}$-integrins on THP-1 surfaces. Time course effects of the levels of total $\beta_{1}$-integrin (a) or the activated isoform of $\beta_{1}$-integrin (b) on THP-1 cells stimulated with IDR-1002 $(50 \mu \mathrm{g} / \mathrm{ml})$. Detection of integrin levels were done by staining with an anti-CD29 antibody or a HUTS-4 antibody, which detects the activated conformation of $\beta_{1}$-integrins, and measured by flow cytometry. Data are presented as the mean MFI fold change over basal values $( \pm S E)$ of at least 5 independent experiments. Student's two-tailed t test: ${ }^{*} \mathrm{p}<0.05 ;{ }^{* *} \mathrm{p}<0.01 ;{ }^{* * *} \mathrm{p}<0.001$.

peptide-mediated adhesion. Our results suggest that the IDR-1002-induced adhesion of THP-1 cells to fibronectin is dependent on $\beta_{1}$-integrin activity, supporting the previous observation that $\beta_{1}$-integrins play a large role in peptide-mediated enhancement of monocyte chemotaxis on fibronectin.

\section{$\beta_{1}$-Integrin Regulation by IDR-1002}

Due to the $\beta_{1}$-integrin dependency of peptide-mediated effects on monocyte-fibronectin adhesion and migration, the regulation of $\beta_{1}$-integrins by IDR-1002 was assessed. The effects of IDR-1002 on the overall expression levels of $\beta_{1}$-integrins on monocyte surfaces were investigated by measuring the levels of CD29, the $\beta$-subunit of $\beta_{1}$-integrin heterodimers, on THP-1 cells. THP-1 cells were stimulated with IDR-1002 for various time intervals prior to assessment of $\beta_{1}$-integrin levels. Over the course of $4 \mathrm{~h}$, there was no substantial change in overall $\beta_{1}$-integrin levels (fig. 4a). However, integrin function can be differentially regulated via multiple processes, including the conformational change of resting integrins to a higher-affinity state, termed integrin activation [7]. THP-1 cells stimulated with IDR-1002 displayed a transient increase in levels of activated $\beta_{1}$-integrins, as determined by staining with the HUTS- 4 antibody, which specifically targets $\beta_{1}$-integrin in its activated conformation [16].
Integrin activation was detectable as early as $15 \mathrm{~min}$ and peaked at $30 \mathrm{~min}$, showing a $50 \%$ increase over unstimulated controls (fig. 4b). Levels of $\beta_{1}$-integrin activation decreased after $60 \mathrm{~min}$ before returning to unstimulated levels after $4 \mathrm{~h}$. Thus while IDR-1002 had no major effect on the expression of total $\beta_{1}$-integrin surface levels, it induced the transient activation of $\beta_{1}$-integrins from a lowaffinity state to a high-affinity one.

\section{Role of the PI3K-Akt Pathway in IDR-1002}

Enhancement of Adhesion and $\beta_{1}$-Integrin Regulation

The PI3K-Akt pathway has been shown to play a major role in regulating cellular adhesion [13, 17-22]. As IDR1002-mediated chemokine regulation in human PBMCs is dependent on the PI3K pathway [4], we inquired whether IDR-1002 activated the PI3K-Akt pathway in human monocytes and whether this resulted in the regulation of monocyte adhesion. PI3K activation was determined by measuring the levels of Akt phosphorylation in THP-1 cells. THP-1 cells were stimulated with IDR-1002 for varying time intervals prior to assessment of intracellular phospho-Akt levels. IDR-1002-stimulated THP-1 cells demonstrated a rapid increase in Akt phosphorylation, peaking at $15 \mathrm{~min}$ with a 2 -fold increase in phosphorylation over unstimulated controls (fig. 5a). Elevated phospho-Akt levels persisted until $4 \mathrm{~h}$ after treatment exhibit- 

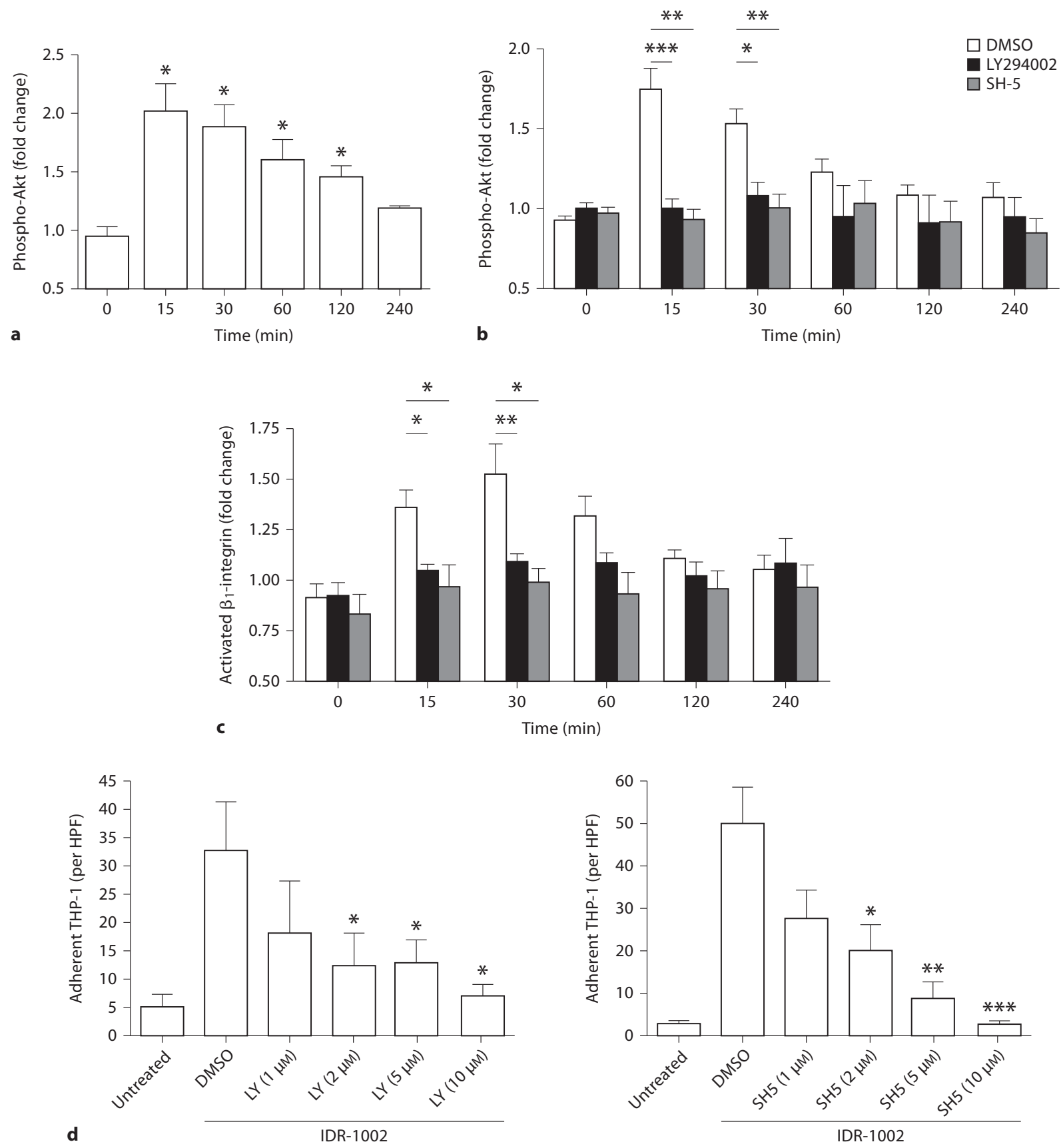

Fig. 5. The role of the PI3K-Akt pathway in IDR-1002-mediated adhesion of THP-1 cells to fibronectin. a Time course effects on Akt Ser-473 phosphorylation in THP-1 cells stimulated with IDR$1002(50 \mu \mathrm{g} / \mathrm{ml})$. Phospho-Akt levels were assessed by intracellular staining with an anti-phospho-Akt antibody and detected by flow cytometry. $\mathbf{b}, \mathbf{c}$ The effects of PI3K-Akt inhibitors on IDR1002-mediated Akt phosphorylation (b) or $\beta_{1}$-integrin activation (c) in THP-1 cells. THP-1 cells were pretreated for $1 \mathrm{~h}$ with PI3K inhibitor LY294002 $(10 \mu \mathrm{m})$, Akt inhibitor SH-5 $(10 \mu \mathrm{m})$ or $0.1 \%$ DMSO as a vehicle control, and stimulated with IDR-1002 $(50 \mu \mathrm{g} /$ $\mathrm{ml}$ ) prior to measurement of intracellular phospho-Akt levels or surface activated $\beta_{1}$-integrin levels. d Dose-dependent effects of PI3K and Akt inhibition on fibronectin adhesion by THP-1 cells stimulated with IDR-1002 (50 $\mu \mathrm{g} / \mathrm{ml})$. THP-1 cells were pretreated for $1 \mathrm{~h}$ with LY294002, SH-5 or 0.1\% DMSO and stimulated with IDR-1002 $(50 \mu \mathrm{g} / \mathrm{ml})$ for $3 \mathrm{~h}$ and assayed for their ability to adhere. Data are presented as the mean MFI fold change over basal values $(\mathbf{a}-\mathbf{c})$ or the mean of adherent cells $(\mathbf{d})$ per HPF $( \pm$ SE) of at least 5 independent experiments. Student's two-tailed t test: ${ }^{*} \mathrm{p}<0.05 ;{ }^{* *} \mathrm{p}<0.01 ;{ }^{* * *} \mathrm{p}<0.001$. 
ing a similar kinetic profile to that of IDR-1002-induced $\beta_{1}$-integrin activation. This effect was abrogated in THP1 cells pretreated for $1 \mathrm{~h}$ with LY294002, a PI3K-specific inhibitor, demonstrating a PI3K-dependent activation of Akt by IDR-1002 (fig. 5b).

To determine the involvement of the PI3K-Akt pathway in IDR-1002-mediated monocyte adhesion to fibronectin, adhesion experiments were repeated using THP1 cells pretreated with PI3K inhibitor LY294002 and Aktspecific inhibitor SH-5 for $1 \mathrm{~h}$ prior to stimulation with IDR-1002. The addition of a PI3K or an Akt inhibitor reduced peptide-induced monocyte adhesion to fibronectin in a dose-dependent manner compared to a DMSO pretreatment control (fig. 5d). Complete elimination of the adhesive response by either inhibitor occurred at concentrations of $10 \mu \mathrm{m}$, a non-toxic concentration capable of fully inhibiting Akt activation induced by IDR1002. To assess whether other pathways required for IDR-mediated immunomodulation are involved in IDR1002 -induced adhesion, namely the MAPK pathways [3, 4], THP-1 cells were pretreated with the p38 MAPK inhibitor SB203580 or the MEK1 inhibitor PD98059 prior to stimulation of IDR-1002. Inhibition of p38 had no effect on peptide-induced THP-1 fibronectin adhesion (online suppl. fig. 3), while MEK1 inhibition, at high inhibitor concentrations, led to a $40 \%$ reduction in adhesion ( $\mathrm{p}<0.01, \mathrm{n}=5$, online suppl. fig. 3 ). In the absence of peptide stimulation, none of the inhibitors alone affected THP-1 adhesion to fibronectin at any concentration used (data not shown). Overall, it could be concluded that activation of the PI3K-Akt pathway by IDR-1002 is necessary for peptide-mediated monocyte adhesion to fibronectin.

Both PI3K and Akt have been demonstrated to be inside-out signaling activators of various integrin classes, including $\beta_{1}$-integrins $[19,23-25]$. As IDR-1002 promotion of THP-1 adhesion to fibronectin was shown to be PI3K-Akt dependent, the role of the PI3K-Akt pathway in IDR-1002-induced $\beta_{1}$-integrin activation was then investigated. THP-1 cells pretreated with $10 \mu \mathrm{m}$ of LY294002 or SH-5, prior to stimulation with IDR-1002, exhibited no increase in $\beta_{1}$-integrin activation compared to non-peptide-stimulated controls, as measured by HUTS- 4 antibody binding (fig. 5c). In contrast, DMSO-pretreated THP-1 cells, stimulated with IDR-1002, presented transient activation of $\beta_{1}$-integrins over unstimulated controls, demonstrating the necessity of the PI3K-Akt pathway. As pertussis toxin-sensitive $\mathrm{G}_{\mathrm{i}}$-protein signaling was necessary for IDR-1002 induction of chemokines [4], we also investigated whether it was also involved in peptide- mediated integrin activation. THP-1 cells pretreated with $100 \mathrm{ng} / \mathrm{ml}$ of pertussis toxin for $1 \mathrm{~h}$, prior to IDR-1002 stimulation for $30 \mathrm{~min}$, exhibited an increase in $\beta_{1}$-integrin activation similar to THP-1 cells without pertussis toxin pretreatment (online supp. fig. 4). This pertussis toxin pretreatment condition was sufficient to eliminate migration towards chemokines CCL3 and CCL5, confirming an inhibition of $\mathrm{G}_{\mathrm{i}}$-protein functions [unpubl. data]. Taken together, these results indicate that IDR1002 promotes THP-1 binding to fibronectin via the PI3K-Akt pathway, likely through the inside-out activation of $\beta_{1}$-integrins.

\section{Role of the PI3K-Akt Pathway in IDR-1002-Mediated} Enhancement of Monocyte Migration

Having demonstrated that IDR-1002 utilized the PI3K-Akt pathway to promote monocyte interaction with fibronectin via $\beta_{1}$-integrin activation, we investigated whether this pathway played a role in the peptide-mediated enhancement of monocyte chemotaxis. Monocytes were pretreated with $10 \mu \mathrm{m}$ of LY294002 or SH-5 for $1 \mathrm{~h}$ prior to chemotaxis towards monocyte chemokines. The presence of LY294002 or SH-5 reduced baseline spontaneous monocyte migration by 53 and $70 \%$, respectively, compared to DMSO-pretreated controls $(\mathrm{p}<0.05, \mathrm{n}=3)$. In the absence of chemokines, IDR-1002 did not significantly alter monocyte migration in each respective inhibitor treatment (data not shown). Similar to previous experiments, monocytes pretreated with DMSO migrated towards chemokines through a fibronectin-coated membrane, an effect significantly enhanced in the presence of IDR-1002 (fig. 6). However, after LY294002 and SH-5 pretreatment, IDR-1002 had a minimal or no effect on monocyte chemotaxis towards chemokines. It must be noted that LY294002 and SH-5 pretreatment strongly suppressed monocyte chemotactic responses to all chemokines tested, consistent with observations that the PI3K-Akt pathway is a major regulatory axis of monocyte chemotaxis. It is possible that the elimination of IDR1002 enhancement on migration stemmed from a general suppression of the monocyte chemotactic response, masking any prospective PI3K-Akt-independent mechanisms, utilized by IDR-1002. However, in conjunction with results demonstrating the PI3K-Akt-dependent enhancement of monocyte adhesion and integrin activation by IDR-1002, these observations strongly suggested that the PI3K-Akt pathway is central for the enhancement of monocyte chemotaxis by IDR-1002. 

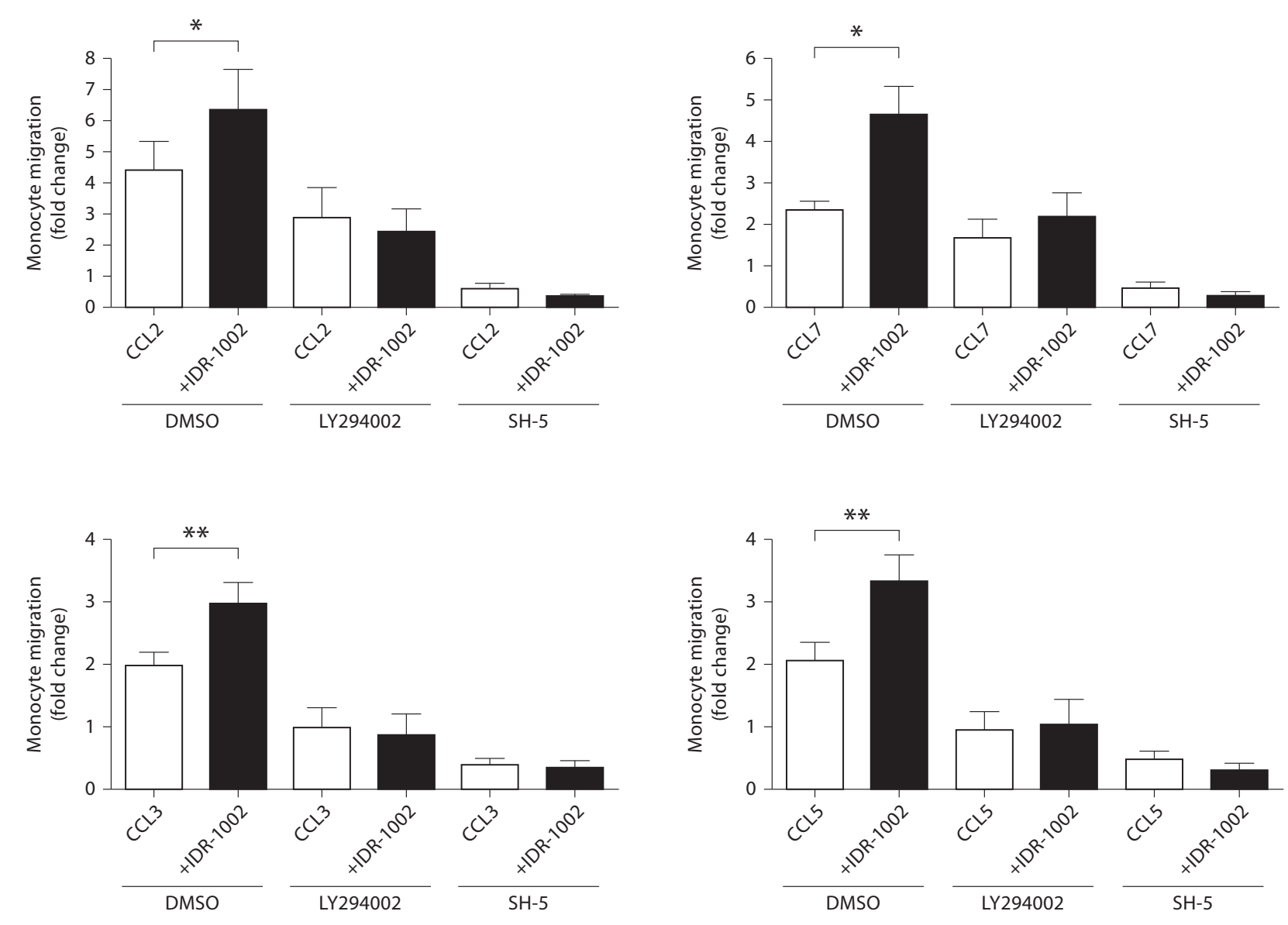

Fig. 6. The role of the PI3K-Akt pathway in IDR-1002-mediated enhancement of monocyte migration. Monocytes were pretreated with the PI3K-inhibitor LY294002 $(10 \mu \mathrm{m})$, Akt-inhibitor SH-5 (10 $\mu \mathrm{m})$ or 0.1\% DMSO for $1 \mathrm{~h}$. Monocytes were then assessed for their ability to migrate towards chemokines $(12.5 \mathrm{ng} / \mathrm{ml})$ through a fibronectin membrane with or without IDR-1002 $(20 \mu \mathrm{g} / \mathrm{ml})$ treatment. Data are presented as fold increases in migration over the migration of DMSO-treated monocytes in media alone $( \pm \mathrm{SE})$ of at least 3 independent experiments, each from independent donors. Student's two-tailed t test: ${ }^{*} \mathrm{p}<0.05 ;{ }^{*} \mathrm{p}<0.01$.

\section{Induction of Monocyte Adhesion to Fibronectin by}

\section{IDR Peptides}

Immunomodulatory IDR peptides exhibit many functional similarities. Anti-infective peptides IDR-1 and IDR-1002 confer in vivo protection against bacterial infections through modulation of innate immune responses, including the regulation of chemokine/cytokine responses and recruitment of monocytes to the site of infection [3, 4]. Likewise, IDR-1018 and IDR-HH2 also demonstrate the ability to modulate the host cytokine/ chemokine environment [26, 27], while both IDR-1002 and IDR-HH2 promote adjuvant activity in formulation
$[5,6]$. We sought to determine whether the ability to promote monocyte adhesion to fibronectin demonstrated by IDR-1002 was shared with other IDR peptides as well. Human monocytes or THP-1 cells were stimulated with IDR peptides or human cathelicidin LL-37, a HDP with similar immunomodulatory functions, and investigated their ability to adhere to fibronectin-coated plates after $3 \mathrm{~h}$. LL-37 was utilized at a concentration of $20 \mu \mathrm{g} / \mathrm{ml}$ as higher concentrations have been associated with observable cytotoxicity in human PBMCs as measured by a lactate dehydrogenase release assay; in contrast, IDR peptides elicited minimal cytotoxicity up to concentrations 


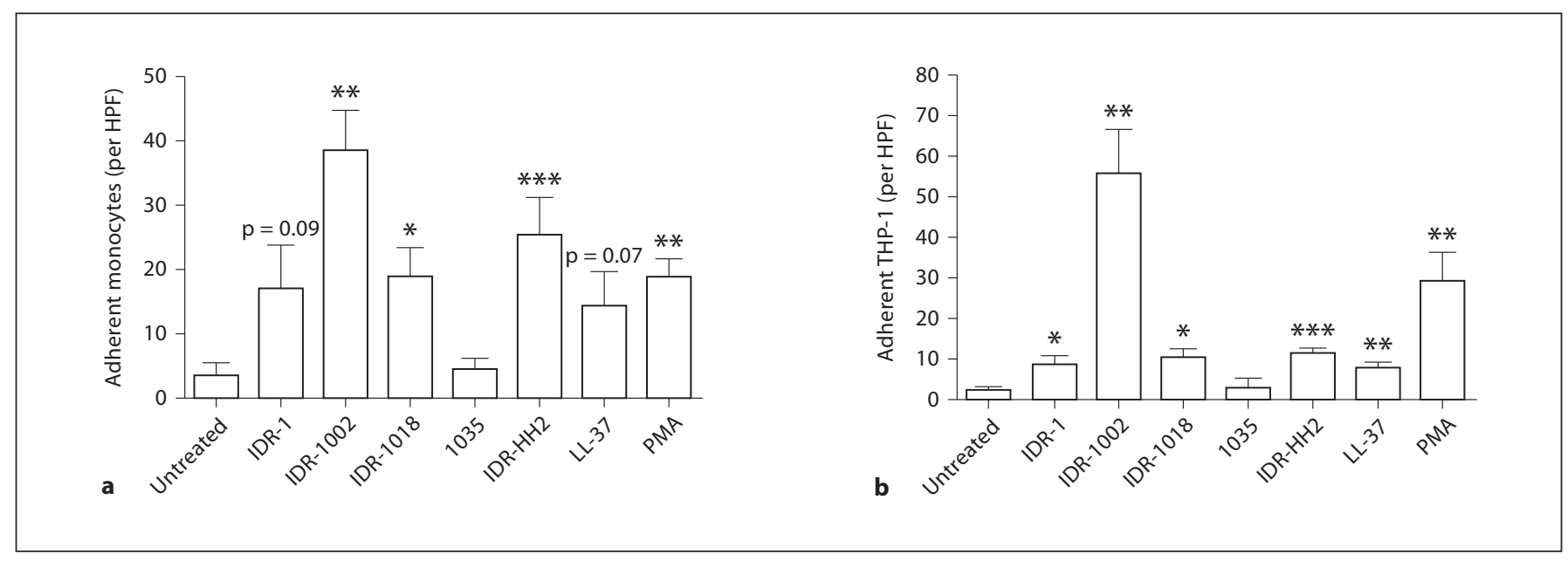

Fig. 7. IDR peptide-induced monocyte adhesion on fibronectin. Human blood monocytes (a) or THP-1 cells (b) were stimulated with IDR peptides $(100 \mu \mathrm{g} / \mathrm{ml})$ or LL-37 $(20 \mu \mathrm{g} / \mathrm{ml})$ for $3 \mathrm{~h}$ and assayed for their ability to adhere to fibronectin-coated plates. Stimulation with $50 \mathrm{ng} / \mathrm{ml}$ of PMA was used as a positive control for inducing monocyte adhesion to fibronectin. Data are presented as the mean of adherent cells per HPF ( \pm SE) of at least 4 independent experiments. In experiments using primary monocytes, each independent experiment utilized cells from an independent donor. Student's two-tailed t test: ${ }^{*} \mathrm{p}<0.05 ;{ }^{* *} \mathrm{p}<0.01 ;{ }^{* *} \mathrm{p}<0.001$.

of $100 \mu \mathrm{g} / \mathrm{ml}$ [unpubl. data]. Treatment with PMA was utilized as a positive control for monocyte-fibronectin adhesion [28]. As show in figure 7, immunomodulatory peptides LL-37, IDR-1, IDR-1002, IDR-1018 and IDR$\mathrm{HH} 2$ promoted monocyte and THP-1 adhesion to fibronectin to varying degrees. IDR-1002 was the most potent adhesion-inducing peptide, promoting monocyte adhesion exceeding that of PMA treatment. Peptide 1035, a negative control peptide isolated as part of the same design series as IDR-1002 but with no immunomodulatory properties as measured by its lack of enhancement of chemokine production in human PBMCs [unpubl. data], did not elicit monocyte or THP-1 adhesion above baseline levels. These results indicate that promotion of monocyte adhesion to fibronectin is a shared property between synthetic immunomodulatory IDR peptides, with IDR peptides stimulating monocyte adhesion at levels comparable to, or exceeding, natural inducers of adhesion.

\section{Discussion}

IDR peptides have a diverse range of regulatory effects on host immunity that can be exploited to enhance protection against bacterial infections and promote adaptive immunity. Our understanding of the range of mechanisms by which IDR peptides and HDPs exert their ef- fects is as yet incomplete, in part due to the diversity of these mechanisms [29]. An increased understanding of the key mechanisms will promote the design of improved immunomodulators as anti-infective agents and adjuvants and their translation into clinical therapies. While a common feature of IDR peptides is their ability to enhance cellular infiltration to sites of infection, mechanistic studies to date have focused on the indirect stimulation of chemotaxis, through the stimulation of chemokine production, rather than any direct effects on cellular motility. In this study, we identified a mechanism by which synthetic peptide IDR-1002 directly enhances monocyte migration, a hallmark effect in IDR-mediated protection against bacterial infection $[3,4]$ and its deployment in adjuvant formulations $[5,6]$. Specifically, we demonstrated that IDR-1002 enhanced monocyte migration towards chemokines through a fibronectin matrix by strengthening the interaction between monocytes and this substrate.

Recruitment of leukocytes to the site of infection is a highly orchestrated and complex event. Mediators of cell recruitment produced during an infection must not only stimulate cellular movement, but also promote cellular attachment to its surrounding environment [7]. Cellular extensions of chemokine-stimulated leukocytes would generate little net movement without an adhesive foothold on which to apply directional force [8]. Many studies 
have shown that leukocyte adhesion to the endothelial surface is a fundamental step in subsequent cellular extravasation and transmigration into tissues [7]. Further localization of leukocytes within tissues also depends on cellular adhesion to the ECM to facilitate movement. We propose that IDR-1002 promotes monocyte recruitment by improving their ability to adhere to substrates. In our study IDR-1002, a peptide which displayed neither direct chemokinetic nor chemoattractive activity, nevertheless enhanced monocyte migration towards a wide range of chemokines through a network of fibronectin, a major ECM component of many tissues. IDR-1002-mediated augmentation was greatly reduced with the functional disruption of the $\beta_{1}$-integrin family, the major monocyte adhesion receptor for fibronectin. This was supported by observations that IDR-1002 induced the potent adhesion of monocytes and THP- 1 cells to fibronectin in a $\beta_{1}$-integrin-dependent manner, correlating with a rapid increase in $\beta_{1}$-integrin activation on THP-1 surfaces. Although we cannot preclude a supportive role of other monocyte fibronectin-binding receptors, such as the $\beta_{2}$ or $\beta_{3}$ families of integrins [30-33], the complete abrogation of adhesion by a $\beta_{1}$-integrin-inhibiting antibody indicates a primary role of $\beta_{1}$-integrins in IDR-1002-mediated adhesion. Overall, these results elucidate a mechanism in which IDR-1002 promotion of $\beta_{1}$-integrin-mediated adhesion results in an enhancement of monocyte movement towards chemotactic signals through fibronectin. It is feasible that in vivo administration of IDR-1002 during a bacterial infection, or as part of an adjuvant formulation, would prime monocytes for enhanced adhesion, and, thus, migration towards chemotactic mediators produced in abundance at the site of infection or immunization. We propose that this effect is independent of the enhancement of recruitment via the promotion of cellular chemokine release, which is observed hours after peptide administration in in vitro and in vivo models [4]. Interestingly, observations that IDR-1002 may enhance monocyte migration towards specific chemokines (CCL3 and CCL 5 but not CCL2 or CCL7), in both a $\beta_{1}$-integrininhibited fibronectin migration model and a non-coatedmembrane migration model, suggest an additional adhesion-independent mechanism by which this peptide can promote monocyte recruitment. This multipronged improvement in monocyte recruitment would account for the increased numbers of monocytes at the infection site and enhanced bacterial clearance elicited by IDR-1002 treatment [4] and enhanced adjuvanticity of formulated pertussis toxoid $[5,6]$.

IDR-1002 Enhances Monocyte Migration and Adhesion on Fibronectin
The regulation of integrin-mediated cellular adhesion is an enormously complex process that involves the actions and interactions of numerous intracellular signaling networks. A diverse array of signaling mediators has been shown to modulate integrin function, including those of the MAPK and PI3K-Akt pathways, the G-protein-coupled receptor and phospholipase $\mathrm{C}$ networks, and the small GTPases Rho and Rap [7, 17-21]. Many of these pathways and networks have been implicated as necessary for certain immunomodulatory effects of natural HDPs [34]. Synthetic IDR peptides, similar to their natural precursors, have demonstrated the ability to regulate immune responses, such as the regulation of chemokine production, through modulation of endogenous pathways [3, 4]. Thus, we hypothesize that modulation of monocyte integrin function and adhesion by IDR-1002 stemmed from its activation of natural signaling pathways; this conclusion is consistent with the observation of a modest responsiveness of THP-1 cells to the human HDP LL-37 (fig. 7). In this study, we observed that the ability of IDR1002 to induce $\beta_{1}$-integrin activation and promote monocyte adhesion and migration on fibronectin was highly dependent on its activation of the PI3K-Akt pathway, demonstrating a link between the modulation of signaling by IDR peptides and the regulation of integrin function. Interestingly, the inhibition of the p38 and MEK1 MAPK pathways, both involved in monocyte integrin regulation and IDR-1002-mediated chemokine regulation in PBMCs, showed no or comparatively minor effects on monocyte adhesion. Similarly, inhibition of $\mathrm{G}_{\mathrm{i}}$-protein function by pertussis toxin, involved in both IDR-1002mediated cytokine induction or chemokine-mediated responses, had no effect on peptide-mediated activation of $\beta_{1}$-integrins. This underscores the complexity by which IDR peptides might modulate specific signaling networks to regulate distinct aspects of immunity. Our understanding of the methods by which IDR peptides and HDPs affect immune signaling activity remains in its infancy. The upstream receptors of IDR peptides which coordinate this IDR-induced signal regulation have not yet been fully elucidated. However, certain IDR peptide receptors have been identified, including the cellular scaffold protein sequestosome-1/p62 and intracellular GAPDH, both important for IDR-1-mediated activation of p38 MAPK [35, 36]. These observations demonstrate that the interaction of IDR peptides with endogenous molecules can result in the downstream regulation of signaling. Certain structural characteristics shared both by HDPs and synthetic IDR peptides, such as their small size, net positive charge and amphiphilic properties, also suggest the potential for

J Innate Immun 2012;4:553-568 
numerous interacting partners. Indeed, HDPs have been shown to utilize different receptors to regulate different aspects of immunity [2]. Therefore, we speculate that IDR peptides, akin to endogenous HDPs, likely utilize a diverse range of endogenous receptors to regulate distinct aspects of the immune response, including the regulation of monocyte integrin function and adhesion.

Although the current study focused on the ability of IDR-1002 to utilize the PI3K-Akt pathway in modulating $\beta_{1}$-integrin affinity via 'inside-out' activation, there are other mechanisms through which this pathway can regulate integrin function. The PI3K-Akt pathway is known to promote the recycling of internalized integrins to the cell surface $[37,38]$, although the lack of effect by IDR-1002 on total surface $\beta_{1}$-integrins levels makes this an unlikely explanation for IDR-1002-enhanced adhesion. However, we cannot exclude the role of PI3K-Akt-mediated increases in integrin avidity via its promotion of integrin mobility and clustering $[39,40]$. Taking into consideration the multiple effects of IDR peptides and natural peptides on cellular signaling, as well as the complexity of interactions within signaling networks, IDR-1002 may affect other signaling networks through cross-talk. For example, in various cell models, PI3K has been shown to activate various small GTPases and phospholipase $\mathrm{C}$, which are among the best-characterized mediators of integrin activation [4145]. Similarly, other signaling pathways used by IDR-1002 are known to impact the PI3K-Akt pathway, including the G-protein-coupled receptor-induced networks. Despite these complexities, we propose that the PI3K-Akt pathway is central to IDR-1002 modulation of $\beta_{1}$-integrin function and subsequent enhancement of monocyte migration and adhesion to fibronectin.

Monocyte adhesion and migration on fibronectin within tissues is only one process coordinating overall leukocyte infiltration. This study provides insights into other mechanisms by which IDR-1002 potentially promotes monocyte mobilization to infectious sites. The $\beta_{1^{-}}$ integrin-activating properties of IDR-1002 may have implications at other stages of monocyte recruitment. VLA4 , a $\beta_{1}$-integrin member, is a well-known receptor for VCAM-1 on endothelial cells and plays a major role in cellular rolling, firm adhesion and transmigration across the endothelia $[46,47]$. In addition, with many similarities between the regulation of $\beta_{1}$-integrins and other integrin family members, it is conceivable that IDR peptides may affect other stages of integrin-mediated adhesion and migration. Indeed we have observed that IDR-1002 promotes THP-1 adhesion to ICAM-1 [unpubl. data], a $\beta_{2}$-integrin-mediated interaction essential for monocyte arrest and adhesion on the endothelial layer [7].

In summary, we established that IDR peptides can promote the adhesion and migration of monocytes to fibronectin through enhanced $\beta_{1}$-integrin function via activation of the PI3K-Akt pathway. This study identifies novel functions of IDR peptides in promoting integrin-mediated monocyte adhesion to fibronectin and synergistically enhancing monocyte migration towards host chemokines, further expanding the repertoire of immune-regulating effects of IDR peptides. Monocyte adhesion not only has implications in monocyte recruitment, but farreaching regulatory functions in many aspects of the host immune response, including wound healing, cellular differentiation and tissue homeostasis, among others. Understanding how IDR peptides regulate monocyte migration, adhesion and integrin function through its effect on cellular signaling networks will aid in the development and optimization of novel agents with improved anti-infective and immunomodulatory functions.

\section{Acknowledgments}

This work was supported by the Canadian Institutes for Health Research and the Foundation for the National Institutes of Health through a grant from the Grand Challenges in Global Health Initiative. R.E.W.H. is the recipient of a Canada Research Chair. We thank Dr. Francois Niyonsaba for his technical assistance.

\section{Disclosure Statement}

The IDR peptides described here have been filed for patent protection by the University of British Columbia and some have been licensed out as adjuvant components while others are being considered for licensing as therapeutics.

References host-defense peptides as new anti-infective therapeutic strategies. Nat Biotechnol 2006; 24:1551-1557.

-2 Mookherjee N, Hancock REW: Cationic host defence peptides: innate immune regulatory peptides as a novel approach for treating infections. Cell Mol Life Sci 2007;64:922-933.

- 3 Scott MG, Dullaghan E, Mookherjee N, Glavas $\mathrm{N}$, Waldbrook M, Thompson A, Wang A, Lee K, Doria S, Hamill P, Yu JJ, Li Y, Donini O, Guarna MM, Finlay BB, North JR, Hancock REW: An anti-infective peptide that selectively modulates the innate immune response. Nat Biotechnol 2007;25:465-472. 
-4 Nijnik A, Madera L, Ma S, Waldbrook M, Elliott MR, Easton DM, Mayer ML, Mullaly SC, Kindrachuk J, Jenssen H, Hancock REW: Synthetic cationic peptide IDR-1002 provides protection against bacterial infections through chemokine induction and enhanced leukocyte recruitment. J Immunol 2010;184: 2539-2550.

5 Gracia A, Polewicz M, Halperin SA, Hancock REW, Potter AA, Babiuk LA, Gerdts V: Antibody responses in adult and neonatal $\mathrm{BALB} / \mathrm{c}$ mice to immunization with novel Bordetella pertussis vaccine formulations. Vaccine 2011;29:1595-1604.

-6 Garlapati S, Eng NF, Kiros TG, Kindrachuk J, Mutwiri GK, Hancock REW, Halperin SA, Potter AA, Babiuk LA, Gerdts V: Immunization with PCEP microparticles containing pertussis toxoid, CpG ODN and a synthetic innate defense regulator peptide induces protective immunity against pertussis. Vaccine 2011;29:6540-6548.

-7 Ley K, Laudanna C, Cybulsky MI, Nourshargh S: Getting to the site of inflammation: the leukocyte adhesion cascade updated. Nat Rev Immunol 2007;7:678-689.

-8 Parsons JT, Horwitz AR, Schwartz MA: Cell adhesion: integrating cytoskeletal dynamics and cellular tension. Nat Rev Mol Cell Biol 2010;11:633-643.

-9 Mookherjee N, Brown KL, Bowdish DM, Doria S, Falsafi R, Hokamp K, Roche FM, $\mathrm{Mu}$ R, Doho GH, Pistolic J, Powers JP, Bryan J, Brinkman FS, Hancock REW: Modulation of the TLR-mediated inflammatory response by the endogenous human host defense peptide LL-37. J Immunol 2006;176: 2455-2464.

$\checkmark 10$ Tsuchiya S, Yamabe M, Yamaguchi Y, Kobayashi Y, Konno T, Tada K: Establishment and characterization of a human acute monocytic leukemia cell line (THP-1). Int J Cancer 1980;26:171-176.

- 11 Matias-Roman S, Galvez BG, Genis L, Yanez-Mo M, de la Rosa G, Sanchez-Mateos P, Sanchez-Madrid F, Arroyo AG: Membrane type 1-matrix metalloproteinase is involved in migration of human monocytes and is regulated through their interaction with fibronectin or endothelium. Blood 2005; 105:3956-3964.

$\checkmark 12$ Hemler ME: VLA proteins in the integrin family: structures, functions, and their role on leukocytes. Annu Rev Immunol 1990;8: 365-400.

13 Hart R, Greaves DR: Chemerin contributes to inflammation by promoting macrophage adhesion to VCAM-1 and fibronectin through clustering of VLA-4 and VLA-5. J Immunol 2010;185:3728-3739.

14 Chan JR, Hyduk SJ, Cybulsky MI: Detecting rapid and transient upregulation of leukocyte integrin affinity induced by chemokines and chemoattractants. J Immunol Methods 2003;273:43-52.
15 Chan JR, Hyduk SJ, Cybulsky MI: Chemoattractants induce a rapid and transient upregulation of monocyte alpha4 integrin affinity for vascular cell adhesion molecule 1 which mediates arrest: an early step in the process of emigration. J Exp Med 2001;193:11491158.

16 Luque A, Gomez M, Puzon W, Takada Y, Sanchez-Madrid F, Cabanas C: Activated conformations of very late activation integrins detected by a group of antibodies (HUTS) specific for a novel regulatory region (355-425) of the common beta 1 chain. J Biol Chem 1996;271:11067-11075.

17 Gerszten RE, Friedrich EB, Matsui T, Hung RR, Li L, Force T, Rosenzweig A: Role of phosphoinositide 3-kinase in monocyte recruitment under flow conditions. J Biol Chem 2001;276:26846-26851.

18 Harokopakis E, Albzreh MH, Martin MH, Hajishengallis G: TLR2 transmodulates monocyte adhesion and transmigration via Racl- and PI3K-mediated inside-out signaling in response to Porphyromonas gingivalis fimbriae. J Immunol 2006;176:7645-7656.

-19 Ferreira AM, Isaacs H, Hayflick JS, Rogers KA, Sandig M: The pl10delta isoform of PI3K differentially regulates beta 1 and beta 2 integrin-mediated monocyte adhesion and spreading and modulates diapedesis. Microcirculation 2006;13:439-456.

20 Navarro A, Anand-Apte B, Tanabe Y, Feldman G, Larner AC: A PI-3 kinase-dependent, Stat1-independent signaling pathway regulates interferon-stimulated monocyte adhesion. J Leukoc Biol 2003;73:540-545.

21 Yamamoto H, Naito Y, Okano M, Kanazawa T, Takematsu H, Kozutsumi Y: Sphingosylphosphorylcholine and lysosulfatide have inverse regulatory functions in monocytic cell differentiation into macrophages. Arch Biochem Biophys 2011;506:83-91.

22 Thamilselvan V, Craig DH, Basson MD: FAK association with multiple signal proteins mediates pressure-induced colon cancer cell adhesion via a Src-dependent PI3K/Akt pathway. FASEB J 2007;21:1730-1741.

23 Katsumi A, Naoe T, Matsushita T, Kaibuchi $\mathrm{K}$, Schwartz MA: Integrin activation and matrix binding mediate cellular responses to mechanical stretch. J Biol Chem 2005;280: 16546-16549.

24 Byzova TV, Goldman CK, Pampori N, Thomas KA, Bett A, Shattil SJ, Plow EF: A mechanism for modulation of cellular responses to VEGF: activation of the integrins. Mol Cell 2000;6:851-860.

25 Somanath PR, Kandel ES, Hay N, Byzova TV: Akt1 signaling regulates integrin activation, matrix recognition, and fibronectin assembly. J Biol Chem 2007;282:22964-22976.
26 Kindrachuk J, Jenssen $H$, Elliott $M$, Townsend R, Nijnik A, Lee SF, Gerdts V, Babiuk LA, Halperin SA, Hancock REW: A novel vaccine adjuvant comprised of a synthetic innate defence regulator peptide and $\mathrm{CpG}$ oligonucleotide links innate and adaptive immunity. Vaccine 2009;27:4662-4671.

27 Wieczorek M, Jenssen H, Kindrachuk J, Scott WR, Elliott M, Hilpert K, Cheng JT, Hancock REW, Straus SK: Structural studies of a peptide with immune modulating and direct antimicrobial activity. Chem Biol 2010;17:970-980.

-28 Semel AC, Seales EC, Singhal A, Eklund EA, Colley KJ, Bellis SL: Hyposialylation of integrins stimulates the activity of myeloid fibronectin receptors. J Biol Chem 2002;277: 32830-32836.

29 Mookherjee N, Hamill P, Gardy J, Blimkie D, Falsafi R, Chikatamarla A, Arenillas DJ, Doria S, Kollmann TR, Hancock REW: Systems biology evaluation of immune responses induced by human host defence peptide LL-37 in mononuclear cells. Mol Biosyst 2009;5:483-496.

30 Chung AS, Gao Q, Kao WJ: Either integrin subunit betal or beta 3 is involved in mediating monocyte adhesion, IL-1beta protein and $\mathrm{mRNA}$ expression in response to surfaces functionalized with fibronectin-derived peptides. J Biomater Sci Polym Ed 2007;18: 713-729.

31 Vacca A, Ria R, Presta M, Ribatti D, Iurlaro M, Merchionne F, Tanghetti E, Dammacco F: Alpha(v)beta(3) integrin engagement modulates cell adhesion, proliferation, and protease secretion in human lymphoid tumor cells. Exp Hematol 2001;29:993-1003.

32 Owen CA, Campbell EJ, Stockley RA: Monocyte adherence to fibronectin: role of CD11/ CD18 integrins and relationship to other monocyte functions. J Leukoc Biol 1992;51: 400-408.

33 Anceriz N, Vandal K, Tessier PA: S100A9 mediates neutrophil adhesion to fibronectin through activation of beta 2 integrins. Biochem Biophys Res Commun 2007;354:8489.

$34 \mathrm{Yu}$ J, Mookherjee N, Wee K, Bowdish DM, Pistolic J, Li Y, Rehaume L, Hancock REW: Host defense peptide LL-37, in synergy with inflammatory mediator IL-1beta, augments immune responses by multiple pathways. J Immunol 2007;179:7684-7691.

-35 Yu HB, Kielczewska A, Rozek A, Takenaka S, Li Y, Thorson L, Hancock REW, Guarna MM, North JR, Foster LJ, Donini O, Finlay BB: Sequestosome-1/p62 is the key intracellular target of innate defense regulator peptide. J Biol Chem 2009;284:36007-36011.

36 Mookherjee N, Lippert DN, Hamill P, Falsafi R, Nijnik A, Kindrachuk J, Pistolic J, Gardy J, Miri P, Naseer M, Foster LJ, Hancock REW: Intracellular receptor for human host defense peptide LL-37 in monocytes. J Immunol 2009;183:2688-2696. 
37 Li J, Ballif BA, Powelka AM, Dai J, Gygi SP, Hsu VW: Phosphorylation of ACAP1 by Akt regulates the stimulation-dependent recycling of integrin beta1 to control cell migration. Dev Cell 2005;9:663-673.

38 Roberts MS, Woods AJ, Dale TC, Van Der Sluijs P, Norman JC: Protein kinase B/Akt acts via glycogen synthase kinase 3 to regulate recycling of alpha $\mathrm{v}$ beta 3 and alpha 5 beta 1 integrins. Mol Cell Biol 2004;24:15051515.

39 Krauss K, Altevogt P: Integrin leukocyte function-associated antigen-1-mediated cell binding can be activated by clustering of membrane rafts. J Biol Chem 1999;274: 36921-36927.

40 Gilcrease MZ, Zhou X, Welch K: Adhesionindependent alpha6beta4 integrin clustering is mediated by phosphatidylinositol 3-kinase. Cancer Res 2004;64:7395-7398.
1 Gratacap MP, Payrastre B, Viala C, Mauco G, Plantavid M, Chap H: Phosphatidylinositol 3,4,5-trisphosphate-dependent stimulation of phospholipase C-gamma2 is an early key event in FcgammaRIIA-mediated activation of human platelets. J Biol Chem 1998;273: 24314-24321.

42 Cozzolino M, Stagni V, Spinardi L, Campioni N, Fiorentini C, Salvati E, Alema S, Salvatore AM: p120 catenin is required for growth factor-dependent cell motility and scattering in epithelial cells. Mol Biol Cell 2003; 14: 1964-1977.

43 Huang S, Chen LY, Zuraw BL, Ye RD, Pan ZK: Chemoattractant-stimulated NF-kap$\mathrm{paB}$ activation is dependent on the low molecular weight GTPase RhoA. J Biol Chem 2001;276:40977-40981
44 Woulfe D, Jiang H, Mortensen R, Yang J, Brass LF: Activation of Rap1B by G(i) family members in platelets. J Biol Chem 2002;277: 23382-23390.

45 Pasquet JM, Bobe R, Gross B, Gratacap MP Tomlinson MG, Payrastre B, Watson SP: A collagen-related peptide regulates phospholipase Cgamma2 via phosphatidylinositol 3-kinase in human platelets. Biochem J 1999; 342(Pt 1):171-177.

46 Meerschaert J, Furie MB: The adhesion molecules used by monocytes for migration across endothelium include CD11a/CD18, CD11b/CD18, and VLA-4 on monocytes and ICAM-1, VCAM-1, and other ligands on endothelium. J Immunol 1995;154:4099-4112.

47 Alon R, Kassner PD, Carr MW, Finger EB, Hemler ME, Springer TA: The integrin VLA-4 supports tethering and rolling in flow on VCAM-1. J Cell Biol 1995;128:12431253. 